\title{
Effect of gamma irradiation on physicochemical properties and microbiological quality of wet yellow noodle fortified with water spinach (Ipomoea aquatica)
}

\author{
1,*Wan Zunairah, W.I., ' Nuradilah, M.P., ${ }^{2}$ Ahmad Zainuri, M.D., ${ }^{1}$ Nor-Khaizura, M.A.R., \\ ${ }^{3}$ Nor Afizah, M., ${ }^{3}$ Ismail-Fitry, M.R., ${ }^{3}$ Radhiah, S. and ${ }^{3}$ Nur Hanani, Z.A. \\ ${ }^{1}$ Department of Food Science, Faculty of Food Science and Technology, Universiti Putra Malaysia, 43400, \\ Serdang, Selangor, Malaysia \\ ${ }^{2}$ Division of Agrotechnology and Bioscience, Malaysian Nuclear Agency, Bangi, 43000 Kajang, Selangor, \\ Malaysia \\ ${ }^{3}$ Department of Food Technology, Faculty of Food Science and Technology, Universiti Putra Malaysia, \\ 43400, Serdang, Selangor, Malaysia
}

\author{
Article history: \\ Received: 4 April 2019 \\ Received in revised form: 18 \\ June 2019 \\ Accepted: 20 June 2019 \\ Available Online: 29 July \\ 2019
}

\section{Keywords:}

Irradiation,

Yellow noodle,

Water spinach,

Physicochemical,

Morphology,

Microbiology

\section{DOI:}

https://doi.org/10.26656/fr.2017.4(1).140

\begin{abstract}
Effect of gamma irradiation on physicochemical properties and microbiological quality of wet water spinach yellow (WYS) noodles were investigated. Water spinach has been substituted with the wheat flour at level 5\%,10\% and 15\% and irradiated at $0 \mathrm{kGy}, 3 \mathrm{kGy}$, $5 \mathrm{kGy}$ and $7 \mathrm{kGy}$ with a dose rate of $34 \mathrm{~Gy} /$ minutes by using Cobalt-60. Gamma irradiation significantly decreased the cooking yield, hardness and lightness while significantly increased cooking loss and breaking length of WYS noodles. All doses of irradiation did not affect the moisture content, $\mathrm{pH}$, water activity, greenness and yellowness of the noodles. Cross sections of WYS noodles were observed under VPSEM at 500X magnification and irradiation gave little changes to starch granules. Increasing substitution level of water spinach and irradiation dose showed elongated and clumped together. Moisture content and color of yellow noodles increased gradually on increasing the level of water spinach substituted. However, a decreasing trend was observed in breaking length, hardness, lightness and yellowness. Total plate counts of the WYS noodles that stored at $27^{\circ} \mathrm{C}$ were examined at day 0,3 and 5 . It showed that certain dose such as $7 \mathrm{kGy}$ of irradiation able to reduce the bacteria count in noodles. On day 5 , most of the samples showed high bacteria count more than $10^{8} \mathrm{CFU} / \mathrm{g}$ was not safe to be consumed. In conclusion, gamma irradiation and substitution of water spinach gave significantly effect cooking properties, textural properties and lightness while no effect on moisture content, $\mathrm{pH}$, water activity, greenness and yellowness of WYS noodles.
\end{abstract}

\section{Introduction}

Yellow noodles or the other name yellow alkaline noodle is one of the popular types of noodles that were used among Malaysian in making noodles dish. Yellow noodle was originated from China and was introduced to Southeast Asia by immigrants from Conton and Hokkien $(\mathrm{Fu}, 2008)$. Basic ingredients in making yellow noodles are wheat flour, water, alkaline salt and salt (Karim and Sultan, 2015). After mixed the all the ingredient, the dough is sheeted, cut, boiled, cooled by drain the water and oiled.

Yellow noodle is a food product that contains high carbohydrates that comes from wheat. However, it has low amount of other nutrition content for example fiber. Recently, vegetables were widespread and being commercialized. Vegetables are fortified in noodles to improve the nutritional value of it. Besides that, good quality characteristics of yellow noodles must have strong elasticity and low cooking loss (Karim and Sultan, 2015). However, substituted of wheat flour with dried pumpkin powder able to increase the fiber content but it reduces the elasticity and increases the cooking loss (Aukkanit and Sirichokworrakit, 2017). This is because the reduced wheat flour level will reduce the protein content that provides glutenin and gliadin which form a strong gluten network when mixed with water (Li et al., 2014). Different findings were reported by Ho and Che Dahri (2016) increasing the level of substitution with watermelon rind reduced the cooking loss and firmness of yellow noodles.

Water spinach or Ipomoea aquatica is a vegetable 
that commonly found and widely consumed in Malaysia (Igwenyi et al., 2011). It is high in carbohydrates, dietary fiber, mineral and vitamin content that provide a lot of health benefits (Umar et al., 2011). Therefore, it is usually stir-fried and consumed with rice. Water spinach contains high in insoluble fiber than soluble fiber. However, water spinach has low protein content and free of gluten (Umar et al., 2011) which will produce yellow noodles with weaker gluten network and low elasticity.

Other than that, yellow noodle has a short shelf life because of higher moisture content and water activity (Karim and Sultan, 2015). It will spoil if it is not kept in low-temperature condition. In the food industry, commonly chemical preservatives such as potassium sorbate, sodium dehydroacetate and calcium propionate are used to prolong the shelf life (Li et al., 2011). Nowadays, consumer demands for product that free from chemical preservative. Irradiation as a method of preservation has an excellent potential to improve food safety and extend the shelf life (Lacroix et al., 2004).

Irradiation is a process of exposing food to controlled levels of ionizing radiation (high energy electromagnetic waves) to kill harmful bacteria, pests, or parasites, or to preserve its freshness (Lacroix et al., 2004). Cobalt-60 and Cesium-137 are examples of irradiation source used in the irradiation process (Kalyani and Manjula, 2014). The process of food irradiation is often called cold pasteurization or nonthermal treatment because this treatment did not involve heat. According to Jianming (1998), recommended dosage of irradiation for noodles to extend the shelf life is at 8 or $10 \mathrm{kGy}$. However, Li et al. (2011) reported in his study low dose irradiation able to act as disinfection and the best irradiation for noodles is $4 \mathrm{kGy}$. Besides that, irradiation cause breakdown of carbohydrate in starch, pectin, cellulose to simple sugar like glucose and maltose (Dauphin and Saint-Lebe, 1977) and leads to a reduction in the viscosity and loss texture (Dwight and Kersten, 1939). The objective of this research was to determine the effect of gamma irradiation dose on physicochemical properties and microbiological quality of wet yellow noodle fortified with water spinach.

\section{Materials and methods}

\subsection{Water spinach puree preparation}

Water spinach was obtained from supermarket in the local market. It was washed and blanched in boiled water for 10-15 s. Then, the stalks and leaves were cut for every $3 \mathrm{~cm}$. Next, it was blended with water for 3 mins by using blender (Panasonic MX-GM1011). After that, the blended was filtered and squeezed with a muslin cloth to remove water until the moisture content of water spinach puree reached around $80 \%$.

\subsection{Noodle preparation}

Formulations of noodles (Table 1) were based on the methods by Aukkanit and Sirichokworrakit (2017) with some modification. The water spinach was substituted for the wheat flour with three levels of substitutions at 5 , 10 and $15 \% \mathrm{w} / \mathrm{w}$. The water spinach was mixed with egg, water, salt and sodium carbonate until dissolved. Then, the mixture was mixed with wheat flour by mixer (Kitchen Aid Pro Stand Mixer, USA) at speed 1 for 1 min $20 \mathrm{~s}$. Continued mixed with speed 2 for 4 mins and followed by hand kneading for 5 mins. The dough was covered with plastic and left resting for 20 mins. The dough was sheeted and cut into noodle strands with 2 $\mathrm{mm}$ in width $\times 1 \mathrm{~mm}$ in thickness by noodle-making machine (Marcato Ampia 150, Italy). The noodles were cooked in boiling water $\left(100 \pm 0.5^{\circ} \mathrm{C}\right)$ for $30-35 \mathrm{~s}$ then it cooled immediately under water for $1 \mathrm{~min}$, drained to remove surplus water and mixed with cooking oil. Then, it packed in sealed polypropylene (PP) and kept in the chiller for further analyses.

Table 1. Formulation for water spinach yellow (WSY) noodles

\begin{tabular}{lccc}
\hline \multicolumn{1}{c}{ Ingredient } & $5 \% \mathrm{WSY}$ & $10 \% \mathrm{WSY}$ & $15 \% \mathrm{WSY}$ \\
\hline Wheat flour & $95 \mathrm{~g}$ & $90 \mathrm{~g}$ & $85 \mathrm{~g}$ \\
Water spinach (WS) & $5 \mathrm{~g}$ & $10 \mathrm{~g}$ & $15 \mathrm{~g}$ \\
Water & $10 \mathrm{~g}$ & $10 \mathrm{~g}$ & $10 \mathrm{~g}$ \\
Egg & $25 \mathrm{~g}$ & $25 \mathrm{~g}$ & $25 \mathrm{~g}$ \\
Sodium Carbonate & $1 \mathrm{~g}$ & $1 \mathrm{~g}$ & $1 \mathrm{~g}$ \\
Salt & $1 \mathrm{~g}$ & $1 \mathrm{~g}$ & $1 \mathrm{~g}$ \\
Cooking Oil & $10 \mathrm{~g}$ & $10 \mathrm{~g}$ & $10 \mathrm{~g}$ \\
\hline
\end{tabular}

\subsection{Irradiation treatment for the noodles}

The irradiation treatment was done at Sinagama Irradiation Facility, Malaysian Nuclear Agency Bangi, Kajang, Selangor. Each formulation was irradiated at 0 , 3, 5 and $7 \mathrm{kGy}$ by using ${ }^{60} \mathrm{Co}$ source. The dose rate was $34 \mathrm{~Gy} / \mathrm{min}$.

\subsection{Determination of moisture content}

Moisture content of sample was determined according to the oven drying method at temperature $105^{\circ}$ C for 8 hrs. (Zawawi et al., 2014).

\subsection{Determination of $\mathrm{pH}$}

The method was referred to Ho and Che Dahri (2016) with a slight modification of mixing time. Approximately $10 \mathrm{~g}$ of the noodle samples were blended with $100 \mathrm{~mL}$ of distilled water for $1 \mathrm{~min}$. Then, the solution was filtered, and the $\mathrm{pH}$ was measured by using calibrated $\mathrm{pH}$ meter (Jenway 3505, UK). The $\mathrm{pH}$ meter had been calibrated by using buffer solutions of $\mathrm{pH} 4.0$ 
and 7.0 before taking the reading.

\subsection{Determination of water activity}

Water activity of each sample was determined by using Aqualab Model Series 3 TE (Pullman, Washington, USA) at $25^{\circ} \mathrm{C}$.

\subsection{Cooking properties}

The method described by Zawawi et al. (2014) was used to determine cooking yield and cooking loss of noodles. Cooking yield was determined by cooking $10 \mathrm{~g}$ of noodles in a beaker with $150 \mathrm{~mL}$ boiling distilled water for 10 mins by using a hotplate. The beaker was covered with aluminium foil to prevent evaporation and stirred continuously. Then, the cooked noodles were cooled for 15 mins. The noodle was weighted, and the cooking yield was measured by the equation (1) below:

Cooking yield $(\%)=\frac{\text { Weight of noodles after cooking }}{\text { Weight of noodles before cooking }} \times 100$

After that, cooking water was transferred into 250 $\mathrm{mL}$ volumetric flask and distilled water was added until the mark. The volumetric flask was shaken until the cooking water solution homogenized. A total of $10 \mathrm{~mL}$ of the solution was put into a dried crucible and left to dry for a day in oven (Memmert, Germany) at $105^{\circ} \mathrm{C}$. The cooking loss was measured by equation (2) below:

Cooking loss $(\%)=\left(\frac{\mathrm{A}-\mathrm{B}}{\text { Noodle sample weight }-\mathrm{C}}\right) \times 100 \% \times 25$

Where $\mathrm{A}=$ weight of crucible + dry cooked water sample; $\mathrm{B}=$ weight of crucible; and $\mathrm{C}=$ noodles moisture content

\subsection{Color analysis}

Color analysis method was referred from with Zawawi et al. (2014) slight modification. The noodles were packed tightly in $5 \mathrm{~cm} \times 5 \mathrm{~cm}$ sealed translucent plastic bag. The noodles color was determined by calibrated Hunter lab (UltraScan PRO D65, USA). The values of $L^{*}, a^{*}$ and $b^{*}$ were recorded based on CIELAB.

\subsection{Textural properties}

The hardness of noodles was measured using a CT3 Texture Analyzer (TexturePro CT V1.4, USA) fitted with $4.5 \mathrm{~kg}$ load cell and knife edge (clear acrylic $8 \mathrm{~g}, 60$ $\mathrm{mm}$ wide) was used as a probe. A total of five strands of noodles with a length of $5 \mathrm{~cm}$ were rested on the fixture base table and were cut by knife probe at speed of $2 \mathrm{~mm} /$ s. The distance of the probe from the platform was 20 $\mathrm{mm}$. Five replicates of each sample were determined under the TPA test. Same texture analyzer was used for breaking length test with dual grip assembly as a probe. A strand of noodles was griped at both ends by dual grip assembly. Trigger load was $6.0 \mathrm{~g}$. Each sample of triplicates was determined under tension test with pretest, test and return speed at $1 \mathrm{~mm} / \mathrm{s}$ according to method Sirichokworrakit et al. (2015).

\subsection{Morphology observation}

The method was referred to as Sung and Stone (2005) with modification. Morphology of starch granules of the samples was examined using a Variable Pressure Scanning Electron Microscope (LEO 1455 VPSEM, Cambridge, England). The samples were wiped with tissue to remove the oil before attached to the stub using carbon conductive adhesive 502. Then, the samples were dried in oven (Memmert, Germany) at $50^{\circ} \mathrm{C}$ for 5 mins. The cross-section of noodle was observed with a magnification of $500 \mathrm{x}$ and with an accelerating potential of $20 \mathrm{kV}$.

\subsection{Determination of total plate count}

After irradiation, each sample was stored at $27^{\circ} \mathrm{C}$. Total plate counts of the samples were examined for day 0, 3 and 5. Based on method Ghaffar et al. (2009), $25 \mathrm{~g}$ of the sample was mixed with $225 \mathrm{~mL} 0.1 \%$ peptone water in a stomacher bag using a stomacher machine for 120 s. Serial dilutions of the sample by using $0.1 \%$ peptone water were done. $0.1 \mathrm{~mL}$ of the appropriate dilutions were spread onto sterile petri plates containing plate count agar (PCA) plates and then was incubated at $37^{\circ} \mathrm{C}$ for $48 \pm 2 \mathrm{hrs}$.

\subsection{Statistical analysis}

Statistical analyses were conducted using Minitab16. The results obtained from the present study are represented as the mean values of three individual replicates \pm the standard deviation. One-way analysis of variance was performed and significant differences between the mean values were determined using Turkey's tests at a significance level of $p<0.05$.

\section{Results and discussion}

3.1 Effect of gamma irradiation on the physicochemical properties of water spinach noodle

Figure 1 shows the moisture content of $5 \%, 10 \%$ and $15 \%$ WYS noodles with different irradiation dose. Irradiation was not prominent on the moisture content of $5 \%$ and $15 \%$ WYS noodles but gave a significant effect only on the moisture content of $10 \%$ WSY noodles. A similar pattern of results was obtained in Lotus stem starch which moisture content had no significant difference in increased of irradiation dose Gani et al. (2013). Mohd Adzahan et al. (2019) reported moisture loss in irradiated starches were insignificant. This is because, irradiation is a non-thermal process, so moisture 
loss does not occur. However, samples with different levels of water spinach substitution and treated at similar irradiation dose exhibited a significant increase in moisture content, where $15 \%$ WYS noodle has the highest moisture content than $5 \%$ and $10 \%$ WYS noodles. Water spinach consists of $80 \%$ moisture content so the moisture content of the noodles will increase when the water spinach was substituted for the wheat flour (Sirichokworrakit et al., 2015). High moisture content is undesirable because it will decrease the gluten level in the dough, hence decrease the sheeting ability during noodles production (Zawawi et al., 2014).

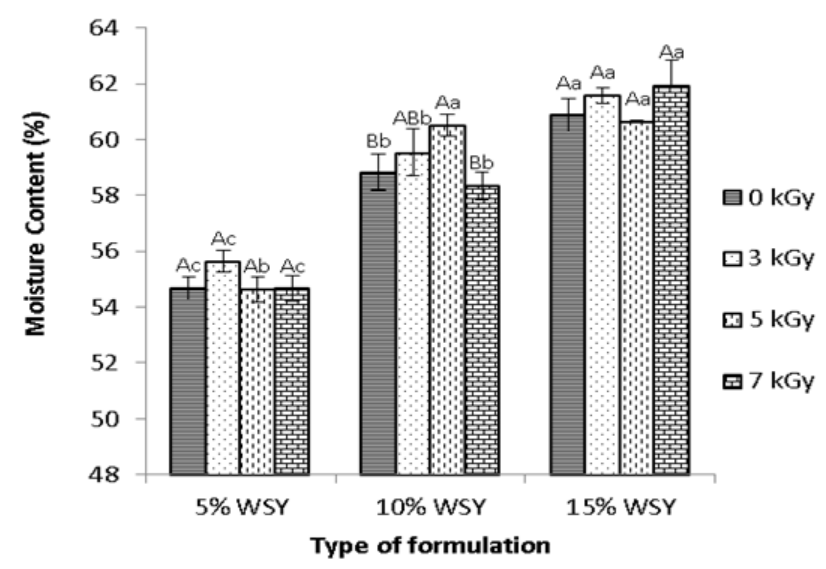

Figure 1. Moisture content of the WSY noodles. Values denoted with the same capital letter are not significantly different $\mathrm{p}<0.05$ among the dose of irradiation with the same formulation. Values with the same small letter are not significantly different $\mathrm{p}<0.05$ among the WSY noodles formulation with the same dose of irradiation.

High $\mathrm{pH}$ value of noodle sample in range 9 to 11 is contributed by alkaline salt used (Miskelly, 1996). It is desirable to produce tougher dough of noodle by strengthening the bonding forces within the starch granules that leads to firmer texture (Ho and Che Dahri, 2016). Table 2 indicates the $\mathrm{pH}$ value of the noodles of the samples. No significant differences in $\mathrm{pH}$ value were observed in noodles treated with different irradiation dose. This result might be due to the low irradiation dose that gave little effect on starch granules. In contrast, Gani et al. $(2012,2013)$ stated that $\mathrm{pH}$ value of starches decreased with increasing of irradiation dose due to the increase of carboxyl content which might form during the breakdown of starch molecules by the action of free radicals.

Water activity reflects the free water present in the food. Higher water activity accelerates the spoilage process if the food is not stored at a low temperature. According to Li et al. (2011), the water activity of wet yellow noodles is 0.979 , a value considered high for water activity hence gives the best condition for bacteria and yeast to grow. Water activity in of WSY noodles with different irradiation dose is shown in Table 3 .
Except for 5\% WSY noodles with 0 kGy irradiation, other WSY noodles had significantly higher water activity that could be due to the presence of water spinach. Increasing irradiation dose and level of water spinach substitution did not give significant differences in water activity for all samples. Similarly, no significant difference in water activity was reported when increasing of irradiation dose in maize and genotypes seed (Yadav and Singh, 2013)

Table 2. $\mathrm{pH}$ value of WSY noodles

\begin{tabular}{cccc}
\hline Dose of & \multicolumn{3}{c}{ Water Spinach Substitute (\%) } \\
\cline { 2 - 4 } Irradiation & $5 \% \mathrm{WSY}$ & $10 \% \mathrm{WSY}$ & $15 \% \mathrm{WSY}$ \\
\hline $0 \mathrm{kGy}$ & $8.95 \pm 0.06^{\mathrm{ABa}}$ & $8.85 \pm 0.01^{\mathrm{Aa}}$ & $8.96 \pm 0.05^{\mathrm{Aa}}$ \\
$3 \mathrm{kGy}$ & $8.87 \pm 0.01^{\mathrm{Bab}}$ & $8.92 \pm 0.01^{\mathrm{Aa}}$ & $8.81 \pm 0.05^{\mathrm{Bb}}$ \\
$5 \mathrm{kGy}$ & $8.92 \pm 0.02^{\mathrm{ABa}}$ & $8.78 \pm 0.19^{\mathrm{Aa}}$ & $8.85 \pm 0.04^{\mathrm{Ba}}$ \\
$7 \mathrm{kGy}$ & $8.98 \pm 0.05^{\mathrm{Aa}}$ & $8.87 \pm 0.01^{\mathrm{Ab}}$ & $8.83 \pm 0.01^{\mathrm{Bb}}$ \\
\hline
\end{tabular}

Values denoted with the same capital alphabet superscript are significantly different $p<0.05$ among the dose of irradiation with the same formulation. Values with the same small alphabet superscript are significantly different $p<0.05$ among the WSY noodles formulation with the same dose of irradiation.

Table 3. Water activity of WSY noodles

\begin{tabular}{cccc}
\hline Dose of & \multicolumn{3}{c}{ Water Spinach Substitute (\%) } \\
\cline { 2 - 4 } Irradiation & $5 \% \mathrm{WSY}$ & $10 \% \mathrm{WSY}$ & $15 \% \mathrm{WSY}$ \\
\hline $0 \mathrm{kGy}$ & $0.986 \pm 0.00^{\mathrm{Ab}}$ & $0.990 \pm 0.00^{\mathrm{Aa}}$ & $0.992 \pm 0.00^{\mathrm{Aa}}$ \\
$3 \mathrm{kGy}$ & $0.988 \pm 0.00^{\mathrm{Aa}}$ & $0.991 \pm 0.00^{\mathrm{Aa}}$ & $0.991 \pm 0.00^{\mathrm{Aa}}$ \\
$5 \mathrm{kGy}$ & $0.990 \pm 0.00^{\mathrm{Aa}}$ & $0.991 \pm 0.00^{\mathrm{Aa}}$ & $0.991 \pm 0.00^{\mathrm{Aa}}$ \\
$7 \mathrm{kGy}$ & $0.989 \pm 0.00^{\mathrm{Aa}}$ & $0.992 \pm 0.00^{\mathrm{Aa}}$ & $0.990 \pm 0.00^{\mathrm{Aa}}$ \\
\hline
\end{tabular}

Values denoted with the same capital alphabet superscript are significantly different $p<0.05$ among the dose of irradiation with the same formulation. Values with the same small alphabet superscript are significantly different $p<0.05$ among the WSY noodles formulation with the same dose of irradiation

\subsection{Cooking properties}

The ability of noodles to absorb water due to the changes during gelatinization of starch increased the cooking yield in noodles (Chin et al. 2012). Regardless of water spinach substitution amount, Figure 2 shows that there was a significant decrease of cooking yield with increased irradiation dose, where $0 \mathrm{kGy}$ had the highest cooking yield than 3,5 and $7 \mathrm{kGy}$. This shows irradiation treatment decreases the cooking yield of WSY noodles. It has been proposed that breakdown of starch occurred during irradiation (Dauphin and SaintLebe, 1977) thus reducing the gelatinization process. The starch granules were elongated and might affect the water absorption in granules. No significant difference in the cooking yield in the noodles was observed when water spinach substitute in the noodles increased for 5 , 10 and $15 \%$. The low-dose irradiation did not cause any changes in water and fiber content in food products 


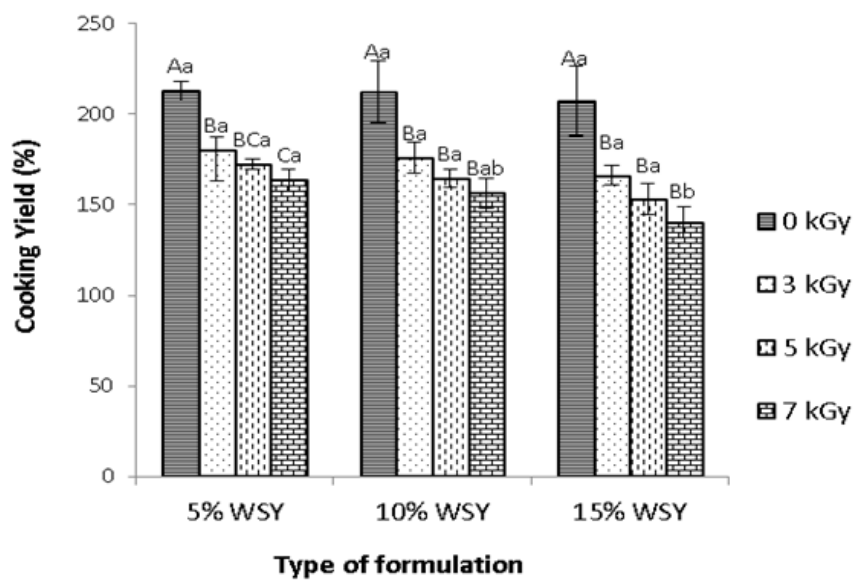

Figure 2. Cooking yield of WSY noodles. Values denoted with the same capital letter are not significantly different $\mathrm{p}<0.05$ among the dose of irradiation with the same formulation. Values with the same small letter are not significantly different $\mathrm{p}<0.05$ among the WSY noodles formulation with the same dose of irradiation.

The cooking loss reflects the amount of starch component that diffused out from the noodles to water during cooking and high value of it is undesirable (Chin et al., 2012). Increasing of cooking loss is indicative of a weak gluten network. Figure 3 shows there was significantly greater cooking loss with increasing irradiation dose. Similarly, Azzeh and Amr (2009) reported a higher cooking loss in noodles when irradiation dose increased attributed to the degradation of starch into simpler compounds such as dextrin, maltose and glucose that is difficult to entrap in gluten network. Besides that, gamma irradiation also causes damage to gluten network (Köksel et al. 1996; Azzeh and Amr, 2009). In contrast, the substitution of water spinach in the noodles did not significantly affect the cooking loss. The water spinach might not interrupt the gluten development during the processing time.

\subsection{Textural properties}

Table 4 shows there was a significant difference in breaking length of the WSY noodles with different irradiation dose. Breaking length of WSY noodles increased when irradiation dose increased implying that noodles treated at higher irradiation are stronger. The strength of noodles is primarily ruled by other factors such as water absorption in starch granules that affects the texture of the noodles. However, the previous study reported increased in irradiation dose cause slight damage to the gluten network (Köksel et al., 1996) which might reduce the breaking length of WYS noodles. Vakil et al. (1973) stated that irradiations of wheat affect the textural properties of food products due to molecular fragmentation of starch and proteins. Based on Table 5, the decreased hardness of irradiated WSY noodles might influence the breaking length of irradiated WSY noodles. The $15 \%$ WSY noodles treated at all

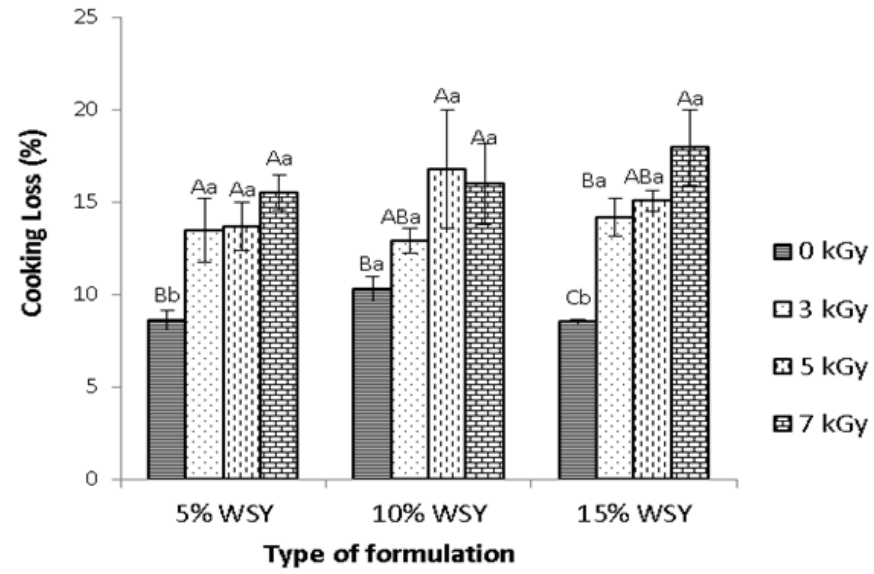

Figure 3. Cooking loss of WSY noodles. Values denoted with the same capital letter are not significantly different $\mathrm{p}<0.05$ among the dose of irradiation with the same formulation. Values with the same small letter are not significantly different $\mathrm{p}<0.05$ among the WSY noodles formulation with the same dose of irradiation.

irradiation dose have the lowest breaking length due to a higher amount of water spinach which disrupts and weaken the gluten network in the noodles. Addition of higher level of WS affects the formation of the gluten network. Same findings also reported when there is a higher level of substitute with wheat flour, the breaking length will decrease due to development of weaker gluten networks (Chin et al. 2012; Aukkanit and Sirichokworrakit, 2017).

Table 4. Breaking length of the WSY noodles

\begin{tabular}{cccc}
\hline Dose of & \multicolumn{3}{c}{ Breaking length (mm) } \\
\cline { 2 - 4 } Irradiation & $5 \%$ WSY & $10 \%$ WSY & $15 \% \mathrm{WSY}$ \\
\hline $0 \mathrm{kGy}$ & $3.23 \pm 0.19^{\mathrm{Ca}}$ & $4.30 \pm 0.26^{\mathrm{Ba}}$ & $2.01 \pm 0.72^{\mathrm{Bb}}$ \\
$3 \mathrm{kGy}$ & $6.86 \pm 0.49^{\mathrm{Ba}}$ & $5.17 \pm 0.50^{\mathrm{ABb}}$ & $2.89 \pm 0.33^{\mathrm{Bc}}$ \\
$5 \mathrm{kGy}$ & $9.24 \pm 0.56^{\mathrm{Aa}}$ & $5.71 \pm 0.61^{\mathrm{Ab}}$ & $5.46 \pm 0.15^{\mathrm{Ab}}$ \\
$7 \mathrm{kGy}$ & $9.44 \pm 1.41^{\mathrm{Aa}}$ & $4.38 \pm 0.36^{\mathrm{Bb}}$ & $5.42 \pm 0.23^{\mathrm{Ab}}$ \\
\hline
\end{tabular}

Values denoted with the same capital alphabet superscript are significantly different $\mathrm{p}<0.05$ among the dose of irradiation with the same formulation. Values with the same small alphabet superscript are significantly different $p<0.05$ among the WSY noodles formulation with the same dose of irradiation.

According to Zawawi et al. (2014), the hardness of noodles depends on the protein content in the noodle and wheat flour contains $80-90 \%$ gluten of total protein (Khatkar, 2014) which was responsible for the dough strength. Table 5 indicates the hardness of all the noodles samples. As the amount of water spinach increased from $0 \%$ to $15 \%$, the hardness of noodles significantly decreased for all irradiation. This result was because gamma irradiation damages the gluten content (Köksel et al. 1996; Azzeh and Amr, 2009) in the noodles, thus weakened the gluten networks. Besides, irradiation caused the breakdown of starch (Dauphin and SaintLebe, 1977) in the gluten network that makes the network less compact and resulted in softening of 
noodles. Significant differences were observed in the hardness of noodles made with different levels of WS, where 5\% WSY noodles exhibited higher hardness than $10 \%$ and $15 \%$ WSY noodles. $5 \%$ WSY noodles have the highest amount of wheat flour led to higher gluten content which made the texture of noodle hard. Increased dose of irradiation caused the starch to elongate, resulting in increased breaking length. However, irradiation also caused damaged to gluten that weakens the starch-gluten networks, consequently softening the texture of noodles. As a result, the hardness of noodles decreased with the increased dose of irradiation.

Table 5. Hardness of the WSY noodles

\begin{tabular}{cccc}
\hline Dose of & \multicolumn{3}{c}{ Hardness $(\mathrm{g})$} \\
\cline { 2 - 4 } Irradiation & $5 \% \mathrm{WSY}$ & $10 \% \mathrm{WSY}$ & $15 \% \mathrm{WSY}$ \\
\hline $0 \mathrm{kGy}$ & $317.80 \pm 40.50^{\mathrm{Aa}}$ & $242.40 \pm 11.94^{\mathrm{Ab}}$ & $214.80 \pm 15.87^{\mathrm{Ab}}$ \\
$3 \mathrm{kGy}$ & $238.80 \pm 14.95^{\mathrm{Ba}}$ & $197.80 \pm 29.00^{\mathrm{ABb}}$ & $170.28 \pm 14.72^{\mathrm{Bb}}$ \\
$5 \mathrm{kGy}$ & $239.80 \pm 19.29^{\mathrm{Ba}}$ & $189.40 \pm 17.06^{\mathrm{Bb}}$ & $163.70 \pm 24.10^{\mathrm{Bb}}$ \\
$7 \mathrm{kGy}$ & $243.20 \pm 16.32^{\mathrm{Ba}}$ & $204.10 \pm 34.40^{\mathrm{Aaab}}$ & $173.22 \pm 14.56^{\mathrm{Bb}}$ \\
\hline
\end{tabular}

Values denoted with the same capital alphabet superscript are significantly different $\mathrm{p}<0.05$ among the dose of irradiation with the same formulation. Values with the same small alphabet superscript are significantly different $p<0.05$ among the WSY noodles formulation with the same dose of irradiation.

\subsection{Color of noodle}

There were significant differences in lightness $\left(\mathrm{L}^{*}\right)$ of WSY noodles with different irradiation dose as shown in Figure 4. Among the irradiation dose tested, all samples treated at $7 \mathrm{kGy}$ had the darkest noodles strands, reflected by the lowest $\mathrm{L}$ value. Increasing on substituted of water spinach caused the darker in color of noodles. After irradiation, the $\mathrm{L}^{*}$ value decreased, probably due to the Maillard reaction between sugars and protein residues (Lee et al. 2003) or transformation of chlorophyll content (Sokhey et al. 1993) exposed to radiation at higher dosage.

Figure 5 indicates the $\mathrm{a}^{*}$ of all the noodles. a* indicates greenness in WSY noodles. The 5\% and $15 \%$ WSY noodles showed no significant differences in $\mathrm{a}^{*}$ among different irradiation dose. Significant differences
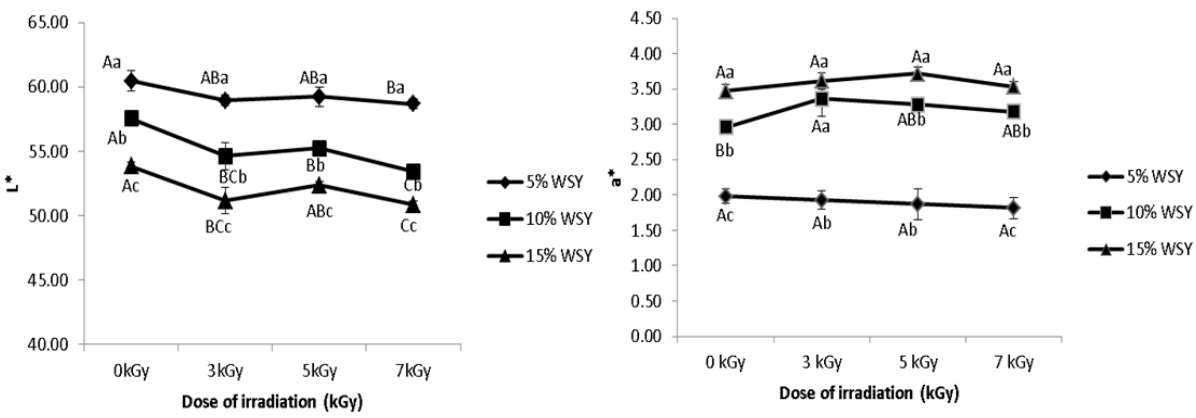

Figure 4. $\mathrm{L}^{*}$ value for the WSY noodles. Figure 5. $\mathrm{a}^{*}$ value for the WSY noodles. were observed in the greenness among the formulation, where $a^{*}$ increased when water spinach substitute level increased this sentence somewhat contradict with line 299-300. This is because water spinach provides chlorophyll pigment in the noodles.

$\mathrm{b}^{*}$ indicates yellowness of the noodles. Yellowish color appearance for noodle is attributed by the presence of natural flavonoid pigments in flour, which is colorless at acidic $\mathrm{pH}$ levels but turns to yellow at alkaline $\mathrm{pH}$ levels (Fu, 2008). Figure 6 shows $\mathrm{b}^{*}$ of the WSY noodles. Dosage of $7 \mathrm{kGy}$ gamma irradiation caused a significant decrease of $\mathrm{b}^{*}$ for $10 \%$ and $15 \%$ WSY noodles. Gamma irradiation may cause color degradation in noodles.

\subsection{Morphology of cross-section in the noodles}

The scanning electron micrographs of the wheat starch granules in noodles were shown in Figure 7, 8 and 9. The wheat starch granules had spherical and oval shapes with smooth surfaces for non-irradiated noodles. There were no obvious changes or signs of damage on the starch granules shape and surfaces when irradiated at 3 and $5 \mathrm{kGy}$. However, the starch granules with higher irradiation dose and water spinach substitution have caused imperfections on their external structures such as the shape became elongated, dented and rougher than the surface of non-irradiated samples. Wheat starch contains two different starch granule size which is large size (type A) $>10 \mu \mathrm{m}$ and small size (type B) $<10 \mu \mathrm{m}$ (Zhang et al., 2013) - $a$ and $b$ type shows the diffraction pattern, not the size of granules. According to Gani et al. (2013), the irradiated starch from $0 \mathrm{kGy}$ to $20 \mathrm{kGy}$ showed no significant change in starch granules. However, increasing substitution of water spinach show starch granules clumping together.

\subsection{Microbiological changes}

The level of $10^{6} \mathrm{CFU} / \mathrm{g}$ is the maximum colony count in fresh noodles that are indicated as limitation for consumer (Lacroix et al. 2004; Ghaffar et al. 2009; Li et

Values denoted with the same capital letter are not significantly different $p<0.05$ among the dose of irradiation with the same formulation. Values with the same small letter are not significantly different $p<0.05$ among the WSY noodles formulation with the same dose of irradiation. 

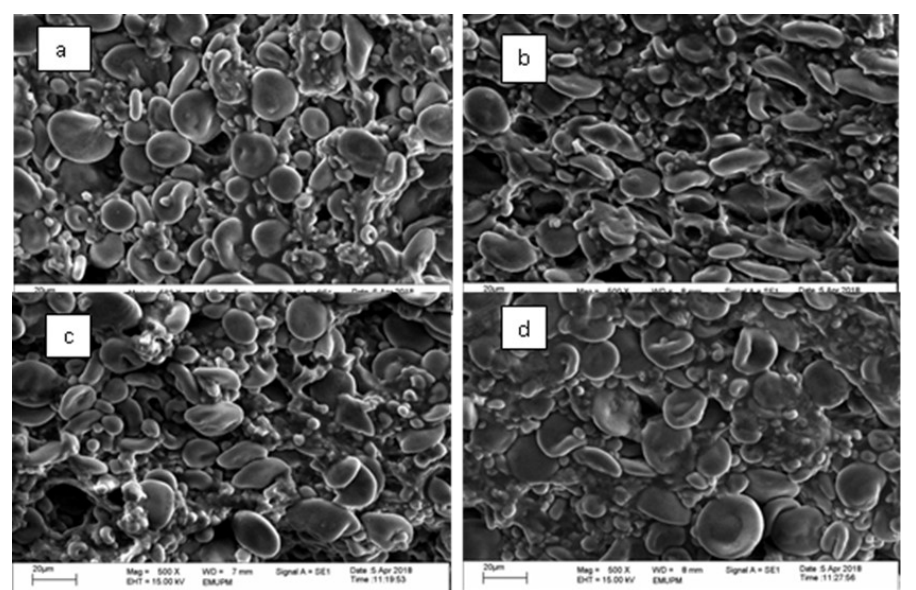

Figure 7. Morphology of cross section 5\% WSY noodles for different dose of irradiation a) 0 kGy b) 3 kGy c) 5 kGy d) 7 kGy at 500x magnificent
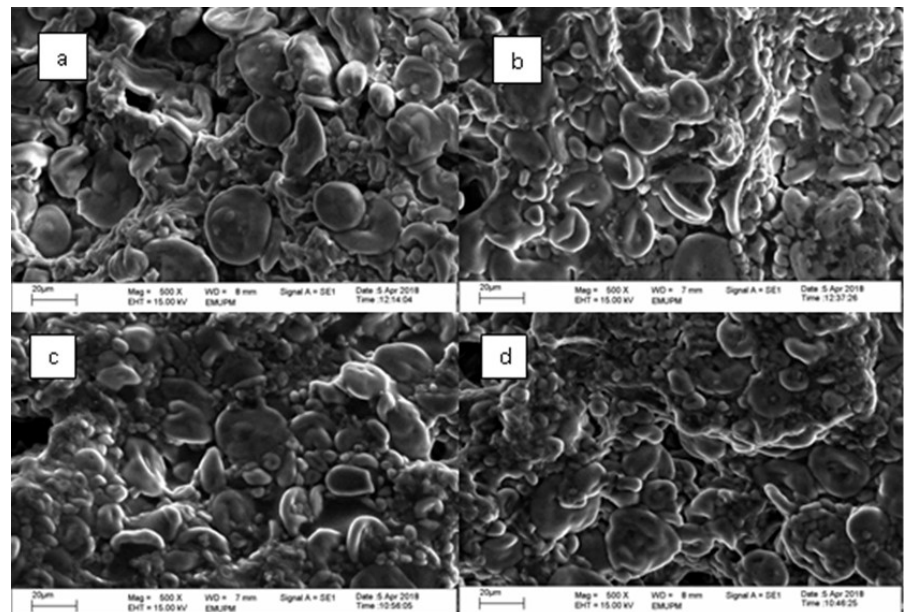

Figure 9. Morphology of cross section 15\% WSY noodles for different dose of irradiation a) $0 \mathrm{kGy}$ b) $3 \mathrm{kGy}$ c) $5 \mathrm{kGy}$ d) 7 kGy at 500x magnificent.

al. 2011). Table 6 shows the TPC of WSY noodles after stored at $27^{\circ} \mathrm{C}$ for 5 days. It showed that certain dose such as $7 \mathrm{kGy}$ able to reduce bacteria count in noodles. On day 5, 15\% WYS noodles for all irradiated dose were spoiled and most of the samples were not safe to be consumed. This might due to high moisture content and water activity in the WYS noodles which accelerate the growth of microorganisms. Li et al. (2011) stated combination of reduced water activity and lower irradiation dose in noodles can prolong the shelf life of fresh noodles for more than a week. The maximum shelf life of fresh yellow noodles is about two weeks.

\section{Conclusion}

In conclusion, gamma irradiation had significantly changed some of the physicochemical properties and microbial quality of WYS noodles. Regardless of water spinach amount in noodles, increasing the irradiation dosage caused increased breaking length and lowered hardness. Increased of dose irradiation resulted in the increased of breaking length and decreased in hardness. The irradiation caused changes in the starch-gluten network by softening the noodle texture. However,

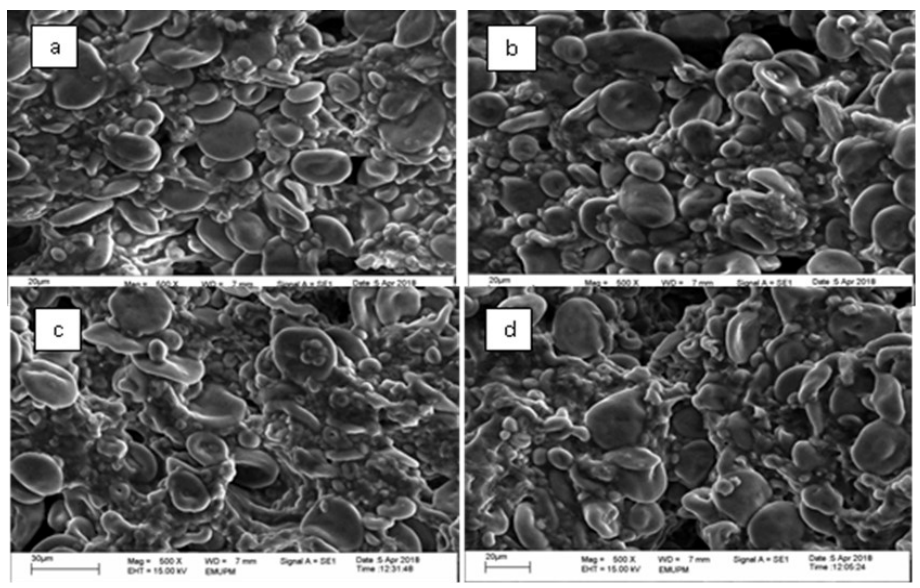

Figure 8. Morphology of cross section $10 \%$ WSY noodles for different dose of irradiation a) 0 kGy b) 3 kGy c) 5 kGy d) 7 kGy at 500x magnificent

Table 6. Total plate count of the water spinach noodles after stored at $27^{\circ} \mathrm{C}$ for 5 days

\begin{tabular}{cccc}
\hline \multirow{2}{*}{ Sample } & \multicolumn{3}{c}{ Total Colony Count $(\log$ CFU/g) } \\
\cline { 2 - 4 } & Day 0 & Day 3 & Day 5 \\
\hline $5 \%, 0 \mathrm{kGy}$ & $3.63 \pm 0.50$ & $8.30 \pm 0.04$ & Spoiled \\
$5 \%, 3 \mathrm{kGy}$ & $<1$ & $6.89 \pm 0.27$ & $7.44 \pm 0.31$ \\
$5 \%, 5 \mathrm{kGy}$ & $<1$ & $6.47 \pm 0.17$ & $7.21 \pm 0.00$ \\
$5 \%, 7 \mathrm{kGy}$ & $<1$ & $3.70 \pm 0.00$ & $5.84 \pm 0.47$ \\
$10 \%, 0 \mathrm{kGy}$ & $3.60 \pm 0.08$ & $8.32 \pm 0.00$ & Spoiled \\
$10 \%, 3 \mathrm{kGy}$ & $<1$ & $8.01 \pm 0.15$ & $7.61 \pm 0.24$ \\
$10 \%, 5 \mathrm{kGy}$ & $<1$ & $5.69 \pm 0.14$ & $5.25 \pm 1.01$ \\
$10 \%, 7 \mathrm{kGy}$ & $<1$ & $3.85 \pm 0.78$ & $7.42 \pm 0.22$ \\
$15 \%, 0 \mathrm{kGy}$ & $3.53 \pm 0.18$ & $8.28 \pm 0.04$ & Spoiled \\
$15 \%, 3 \mathrm{kGy}$ & $<1$ & $8.43 \pm 0.18$ & Spoiled \\
$15 \%, 5 \mathrm{kGy}$ & $<1$ & $6.11 \pm 0.05$ & Spoiled \\
$15 \%, 7 \mathrm{kGy}$ & $<1$ & $4.51 \pm 0.77$ & Spoiled \\
\hline
\end{tabular}

increasing of dose irradiation increased the cooking loss and decreased the cooking yield of the WYS noodle. Physicochemical properties revealed that no significant difference in the moisture content, $\mathrm{pH}$ and water activity of the WYS noodle when the irradiation was applied. Irradiated WYS noodles have lower lightness and it has no significant change in greenness and yellowness. Irradiation showed strong disinfection potential for the noodles. Other than that, most of the WYS noodles spoiled on day 5 and this is due to high moisture content and consequently, water activity in WYS noodles reduced the shelf life. Irradiation gave little changes on starch granule. However, the increasing substitutes of water spinach level starch granules clumping together significantly. Moisture content and greenness of WSY noodles increased gradually on increasing the level of substituted water spinach. Form this study, it can be suggested that irradiation 7-10 kGy will prolong the shelf life of the WS noodles.

\section{Conflict of Interest}

The authors declare no conflict of interest. 


\section{Acknowledgment}

This work was supported by Geran Putra (Grant No. 9550600), which was awarded by the Universiti Putra Malaysia. We gratefully acknowledge the contribution of Malaysian Nuclear Agency Bangi, Selangor for irradiation treatment of WYS noodles

\section{References}

Aukkanit, N. and Sirichokworrakit, S. (2017). Effect of Dried Pumpkin Powder on Physical, Chemical and Sensory Properties of Noodle. International Journal of Advances in Science Engineering and Technology, 5(1), 14-18.

Dauphin, J.F. and Saint-Lebe, L.R. (1977). Radiation chemistry of carbohydrates. In Elias, P.S. and Colen, A.J. (Eds.) Radiation Chemistry of Major Food Components., p. 131-220. Amsterdam, The Netherlands: Elsevier Scientific.

Dwight, C.H. and Kersten, H. (1939). The viscosity of sols made from X-irradiated apple pectin. Journal Physical Chemistry, 42, 1167-1169. https:// doi.org/10.1021/j100904a003

Fu, B.X. (2008). Asian noodles: History, classification, raw materials, and processing. Food Research International, 41(9), 888-902. https:// doi.org/10.1016/j.foodres.2007.11.007

Gani, A., Gazanfar, T., Jan, R., Wani, S.M. and Masoodi, F.A. (2013). Effect of gamma irradiation on the physicochemical and morphological properties of starch extracted from lotus stem harvested from Dal lake of Jammu and Kashmir, India. Journal of the Saudi Society of Agricultural Sciences, 12(2), 109115. https://doi.org/10.1016/j.jssas.2012.08.004

Ghaffar, S., Abdulamir, A.S., Bakar, F.A., Karim, R. and Saari, N. (2009). Microbial growth, sensory characteristic and $\mathrm{pH}$ as potential spoilage indicators of Chinese yellow wet noodles from commercial processing plants. American Journal of Applied Sciences, 6(6), 1059-1066. https://doi.org/10.3844/ ajassp.2009.1059.1066

Ho, L.H. and Che Dahri, N. (2016). Effect of watermelon rind powder on physicochemical, textural, and sensory properties of wet yellow noodles. CyTA - Journal of Food, 14(3), 1-8. https:// doi.org/10.1080/19476337.2015.1134672

Igwenyi, I.O., Offor, C.E., Ajah, D.A., Nwankwo, O.C., Ukaomah, J.I. and Aja, P.M. (2011). Chemical compositions of Ipomoea aquatica (Green kangkong). International Journal of Pharma and Bio Sciences, 2(4), 593-598.

Jianming, C, (1998). Preservation of fresh noodles by irradiation. Radiation Physics and Chemistry, 52(1-
6), 35-38. https://doi.org/10.1016/S0969-806X(98) 00069-3

Kalyani, B. and Manjula, K. (2014). Review Article Food Irradiation - Technology and Application. International Journal of Current Microbiology and Applied Science, 3(4), 549-555.

Karim, R. and Sultan, M.T. (Eds.) (2015). Processing Technology. In Yellow Alkaline Noodles., p. 17-18. USA: Springer International Publishing. https:// doi.org/10.1007/978-3-319-12865-8_5

Lacroix, M., Ouattara, B., Saucier, L., Giroux, M. and Smoragiewicz, W. (2004). Effect of gamma irradiation in presence of ascorbic acid on microbial composition and TBARS concentration of ground beef coated with an edible active coating. Radiation Physics and Chemistry, 71(1-2), 71-75. https:// doi.org/10.1016/j.radphyschem.2004.04.057

Li, M., Zhu, K., Guo, X., Peng, W. and Zhou, H. (2011). Effect of water activity (aw) and irradiation on the shelf-life of fresh noodles. Innovative Food Science and Emerging Technologies, 12(4), 526-530. https:// doi.org/10.1016/j.ifset.2011.06.005

Li, M., Zhu, K.X., Guo, X.N., Brijs, K. and Zhou, H.M. (2014). Natural additives in wheat-based pasta and noodle products: Opportunities for enhanced nutritional and functional properties. Comprehensive Reviews in Food Science and Food Safety, 13(4), 347-357. https://doi.org/10.1111/1541-4337.12066

Sirichokworrakit, S., Phetkhut, J. and Khommoon, A. (2015). Effect of Partial Substitution of Wheat Flour with Riceberry Flour on Quality of Noodles. Procedia - Social and Behavioral Sciences, 197, 1006-1012. https://doi.org/10.1016/ j.sbspro.2015.07.294

Sung, W.C. and Stone, M. (2005). Microstructural studies of pasta and starch pasta. Journal of Marine Science and Technology, 13(2), 83-88.

Umar, K.J., Hassan, L.G., Dangoggo, S.M. and Ladan, M.J. (2007). Thesis of Ipomoea Aquatica.Pdf. Journal of Applied Sciences, 7(6), 803-809. https:// doi.org/10.3923/jas.2007.803.809

Zawawi, N., Gangadharan, P., Ahmad, Zaini R., Samsudin, MG., Karim, R., and Maznah, I. (2014). Nutritional values and cooking quality of defatted Kenaf seeds yellow (DKSY) noodles. International Food Research Journal, 21(2), 603-608. 